Revista Eletrônica de Ciência Administrativa (RECADM) - ISSN 1677-7387

Faculdade Cenecista de Campo Largo - Coordenação do Curso de Administração

v. 4, n. 1, maio/2005 - http://revistas.facecla.com.br/index.php/recadm/

\title{
ESTUDO DE APLICAÇÕES DO BALANCED SCORECARD COMO INSTRUMENTO DE DESDOBRAMENTO ESTRATÉGICO E ALAVANCAGEM DE RESULTADOS
}

\author{
Henrique Martins Rocha ${ }^{1}$
}

\section{RESUMO}

Da busca de um sistema de indicadores de desempenho que permitisse às empresas uma orientação correta no contexto atual, onde mudanças e exigências dos clientes são cada vez mais dinâmicas, surgiu o Balanced Scorecard, um sistema onde medidas financeiras são complementadas com medidas não financeiras e são estabelecidas relações de causa e efeito entre elas. O presente trabalho visa explorar esta metodologia, reunindo informações sobre a mesma e descrevendo os principais conceitos relacionados ao assunto. O estudo exploratório envolve a obtenção de informações teóricas, calcadas numa revisão bibliográfica junto a autores consagrados na abordagem do tema, além de artigos específicos sobre o assunto, seguido da consolidação do tema nas diversas abordagens já publicadas. As conclusões do trabalho indicam que o BSC pode auxiliar a traduzir a estratégia da empresa e pode ser aplicada a organizações de diferentes portes e áreas de atuação.

Palavras chave: Estratégia, excelência, indicadores.

\section{ABSTRACT}

In the search of a performance indicator system, which would enable the companies to sail forth in a correct direction within this new reality, whereby changes and customer demands are increasingly more dynamic, arose the Balanced Scorecard, which is a system whereby financial metrics are complemented with non-financial metrics, and a cause-effect relationship is established among them. The present work has the intent of perform an in-deep analysis of this tool, gathering information on the subject and describing the main concepts related to it. This essay involves the collection of theorybased information, based on a bibliographic review of some renowned authors with expertise on this matter, as well as additional readings, articles and other available publications, followed by the consolidation of the material in the appropriate format. The conclusion indicates that the BSC may help to translate a company's strategy, and which may be applied to differently sized organizations in different operating areas.

Key words: Excellence, indicators, strategy.

\section{INTRODUÇÃO}

Administrar uma organização dentro da realidade atual exige conhecimentos, habilidades, competências, visão estratégica e, principalmente, métodos que possibilitem o suporte ao processo de tomada de decisão (RADÜNZ, 2002). Conforme Chiavenato \& Cerqueira Neto (2003), um novo

\footnotetext{
${ }^{1}$ Professor da Associação Educacional Dom Bosco, Resende/RJ
} 


\section{Revista Eletrônica de Ciência Administrativa (RECADM) - ISSN 1677-7387 Faculdade Cenecista de Campo Largo - Coordenação do Curso de Administração v. 4, n. 1, maio/2005 - http://revistas.facecla.com.br/index.php/recadm/}

mercado está surgindo em muitas economias ocidentais, caracterizado por sofisticados e exigentes clientes em um ambiente competitivo mais volátil e menos previsível.

Conclui-se que as empresas com maior capacidade de reação, ou seja, aquelas que conseguem aumentar a taxa de inovação, lançar novos bens e serviços mais rapidamente, atender a demanda com tempos de espera menores e conquistar maior confiabilidade, são as que tem maior chance de sucesso. Mas isso será totalmente improvável se a empresa não dispõe de um sistema eficaz de gestão do desempenho. A crescente competição tem levado as empresas a buscarem e aperfeiçoarem seus métodos de monitoramento e indicadores de desempenho. Tais indicadores deveriam orientar as decisões e ações dos executivos, desde que estivessem alinhados com os objetivos estratégicos, Visão e Missão da Organização. No entanto, percebe-se um grande vazio entre a declaração de missão e as ações cotidianas dos funcionários.

Phadnis (2001) alerta sobre os cuidados que devem ser tomados ao se determinar o que medir: os indicadores devem ser baseados, na realidade, no que deve ser medido para melhorar os processos, ao invés de simplesmente o que se encaixa no atual sistema de medição. Os indicadores tem de ser verificados com relação ao valor que eles adicionam no entendimento do processo. No entanto, conforme Sauaia (2000), as áreas funcionais são tratadas de maneira estática, como se fossem independentes, o que representa uma grande simplificação da problemática das empresas. Segundo Andrew van Zyl, da Human Capital Corporation, aproximadamente 80\% dos trabalhadores não tem idéia de como sua produtividade (ou falta dela) afeta o negócio e menos de 5\% dos gerentes e supervisores tem a habilidade para comunicar ao grupo os fatores chave para produtividade e performance que afetam o valor para os acionistas (AFRICA NEWS SERVICE, 2001). Há muito pouco conhecimento dos objetivos globais da empresa e da contribuição e integração das diferentes áreas funcionais: os funcionários da linha de frente precisam compreender as conseqüências financeiras de suas decisões e ações, e os altos executivos, reconhecer os vetores de sucesso a longo prazo (CHIAVENATO \& CERQUEIRA NETO, 2003). Neste cenário, a falta de interação entre as diversas partes das organizações traz impactos imediatos em seus custos, tempo de processamento, qualidade de produtos e serviços, etc., deixando estas organizações em desvantagem perante as que utilizam melhor os recursos disponíveis e, de uma forma mais sábia e eficiente, buscam a conquista dos consumidores.

Na administração de negócios, a abordagem matemática e quantitativa trouxe um incrível variedade de instrumentos e ferramentas de mensuração: medir, estimar, avaliar, monitorar, controlar, supervisionar, acompanhar são os termos mais utilizados e, sem dúvida alguma, o balanço contábil e as demonstrações financeiras são, de longe, as medidas mais utilizadas nas nossas organizações, sendo conhecidas, no entanto, suas restrições mais evidentes: voltadas apenas para os ativos tangíveis, físicos e concretos, centradas na realidade passada, com foco quantitativo e tentativa de projeção do passado para o futuro, com base na extrapolação de dados históricos passados. Ou seja, com base de referência nas características da era industrial, quando o mundo dos negócios mudava pouco e se caracterizava pela relativa estabilidade e permanência. 


\section{Revista Eletrônica de Ciência Administrativa (RECADM) - ISSN 1677-7387 \\ Faculdade Cenecista de Campo Largo - Coordenação do Curso de Administração v. 4, n. 1, maio/2005 - http://revistas.facecla.com.br/index.php/recadm/}

Assim surge o Balanced Scorecard, um sistema de gestão que permite traduzir a estratégia da empresa em medidas de desempenho. Ele mantém os indicadores financeiros e inclui indicadores não-financeiros, integrando também as perspectivas dos clientes/mercado, dos processos internos e do aprendizado e crescimento, que em conjunto, contribuirão para os resultados financeiros. Tal sistema permite que a estratégia passe a fazer parte da gestão do dia a dia da empresa, ampliando a visão para além do orçamento anual, introduzindo nos instrumentos de gestão a perspectiva de resultados presentes e o seu impacto futuro.

O presente trabalho visa explorar a metodologia do Balanced Scorecard, avaliando sua potencialidade de alavancar a performance de organizações de diversos portes e setores, ao auxiliar a traduzir a estratégia da empresa e fazer seu desdobramento de forma eficáz.

\section{REVISÃO DE LITERATURA}

Robert Kaplan e David Norton, ambos professores da Harvard Business School, analisavam em 1989 os dados da amostra recolhida de 12 empresas, para estudar e pesquisar sobre medição de desempenho. $O$ desafio era encontrar uma maneira de melhorar o desempenho das empresas e 0 problema investigado era se as empresas se concentravam demasiado na medição financeira e se isso estava lhes causando sérios problemas, pois tomavam decisões inadequadas para seu futuro. A idéia da pesquisa era achar uma maneira de alargar o foco do curto prazo para outro que, mais equilibrado, levasse as empresas a fazerem a coisas certas para ter sucesso, pois o foco exclusivamente financeiro dos diversos sistemas de gestão não espelha a real situação da empresa e, normalmente, aponta para desempenhos passados, com impacto apenas no curto prazo, eminentemente operacional.

Com a publicação em 1992 de um artigo no Harvard Business Review, intitulado "The Balanced Scorecard that Drive Performance", tomou-se conhecimento desta ferramenta e, com seu uso continuado por algumas organizações, sempre sob a orientação de seus criadores, Norton e Kaplan, a mesma foi sendo aprimorada, migrando principalmente de seu conceito inicial de ferramenta de medição de desempenho, para o uso mais nobre de esclarecer e comunicar a estratégia, mas também para gerenciá-la. Em 1993 foi publicado um segundo artigo, intitulado "Putting the Balanced Scorecard to Work" (PRADO, 2002).

Conforme Padro (2002), o conceito do Balanced Scorecard pode ter surgido na França nos anos sessenta, onde se utilizava uma ferramenta chamada Tableau de Bord. Era uma tabela que incorporava diversos rateios para controle financeiro da empresa e, com o passar do tempo, passou a incorporar também indicadores não financeiros, que permitiam controlar também os diferentes processos de negócios. Nos Estados Unidos, também na mesma década, a General Electric desenvolveu uma tabela de controle para gerenciar os processos de negócios da empresa, a partir de oito áreas chaves de resultados, que incluíam temas como rentabilidade, parcela de mercado, formação e responsabilidade pública.

Conforme Kaplan \& Norton, apud Profeta \& Goldszmidt (2002), recentemente vimos que algumas companhias foram além da primeira visão do Balanced Scorecard, para descobrir seu valor como 


\section{Revista Eletrônica de Ciência Administrativa (RECADM) - ISSN 1677-7387 Faculdade Cenecista de Campo Largo - Coordenação do Curso de Administração v. 4, n. 1, maio/2005 - http://revistas.facecla.com.br/index.php/recadm/}

pedra angular de um novo sistema de gestão estratégica. Chiavenato \& Cerqueira Neto (2003) desenvolveram estudos no tocante à implementação do Balanced Scorecard nas organizações, integrado-o a outras práticas consagradas de gerenciamento estratégico, como visões complementares, tendo em vista o elevado percentual de insucesso levantado em suas pesquisas.

Os métodos desenvolvidos sobre a elaboração do Balanced Scorecard utilizam, em sua maioria, os grandes conglomerados como modelos dos seus relatos de aplicações práticas e teóricas. Ao implementar o Balanced Scorecard numa empresa de pequeno porte, Soares (2001) notou a dificuldade de seguir rigidamente os passos propostos por Kaplan \& Norton, surgindo a necessidade da elaboração de uma proposta que levasse em consideração as características e recursos disponíveis pertinentes às pequenas empresas.

Já Matheus (2002) e Pacífico et al (2002), utilizaram o Balanced Scorecard como ferramenta de estruturação e controle de projetos de investimento. Santana (2002), estendeu o conceito de relações de causa e efeito existentes no Balanced Scorecard, ao identificar, no ramo de supermercado, a contribuição de cada um dos indicadores na composição total do valor de mercado adicionado calculado (MVAC), composto pelo valor econômico agregado (EVA) dividido pelo custo ponderado de capital (WACC), disposto então em uma mapa estratégico, através do qual as relações de causa e efeito estão identificadas em percentuais de participação, permitindo que os colaboradores pudessem enxergar as suas colaborações na agregação de valor. Já Kallás (2001) estudou formas de garantir a integridade dos relacionamentos entre os processos internos e os objetivos mercadológicos, principalmente no que se refere à proposição de valor aos clientes, utilizando para isso a abordagem do comportamento do consumidor proposta por Lancaster $(1966,1991)$, ao defender que os consumidores buscam utilidade não nos produtos, mas sim das características ou atributos que estes venham a apresentar e, desta forma, a demanda por um produto resulta dos desejos de vários atributos.

Hernandes (2000) defende que a gestão do conhecimento, descrito como o processo pelo qual uma organização consciente e sistematicamente coleta, cria, organiza, compartilha e quantifica seu acervo de conhecimentos para atingir seus objetivos estratégicos, completa a visão do Balanced Scorecard. Da mesma forma, Lourenço \& Machado (2002), ao discutirem a aplicabilidade do Balanced Scorecard como ferramenta auxiliar ao processo de aprendizagem organizacional, defendem que todos na organização possuam um claro entendimento sobre as hipóteses básicas associadas às estratégias, de forma a permitir um alinhamento entre todas as unidades organizacionais e seus recursos, mediante testes contínuos dessas unidades e a obtenção de resultados passíveis de provocarem adaptações sempre que for necessário.

Cordeiro et al (2002) defendem a integração do Balanced Scorecard com o gerenciamento de processos e marketing de relacionamento: nas organizações prestadoras de serviços, a qualidade é dependente da interação organização/cliente, onde o consumidor tende a avaliar a qualidade de um serviço não somente pela qualidade técnica, mas também pela qualidade funcional. É nesse contexto que o marketing de relacionamento está inserido na gestão estratégica - para diferenciar a 


\section{Revista Eletrônica de Ciência Administrativa (RECADM) - ISSN 1677-7387 \\ Faculdade Cenecista de Campo Largo - Coordenação do Curso de Administração \\ v. 4, n. 1, maio/2005 - http://revistas.facecla.com.br/index.php/recadm/}

organização dos concorrentes no desenvolvimento de soluções, possibilitando ordenar temas organizacionais e desenvolver metas para os processos que se desdobram em metas para os departamentos, equipes e pessoas, de maneira alinhada à estratégia geral da organização, dando prioridades e alocando recursos em processos que realmente são responsáveis pelos resultados a curto e longo prazo.

Conforme Padro (2002), outra aplicação que encontra respaldo junto aos executivos é o uso do Balanced Scorecard no estabelecimento de remuneração variável, já que é um modelo muito forte de gestão de performance.

Conforme Norton \& Kaplan (1997), o Balanced Scorecard deve refletir a estrutura da organização para qual a estratégia foi formulada. Assim sendo, o mesmo se prestaria também a estruturas não unitárias, como corporações, joint-ventures, departamentos de apoio em empresas e unidades de negócios, empresas públicas e instituições em fins lucrativos. Koch (2002), em sua implementação do Balanced Scorecard numa cooperativa de Eletrificação Rural, com o compromisso social/comunitário desta, desenvolveu uma arquitetura diferenciada, visando principalmente o progresso e o bem-estar para as famílias rurais, enquanto Sanchez (2002) expõe a utilização do mesmo de forma a estabelecer, de forma sistemática, as metas estratégicas na gestão de organizações hospitalares, na busca pela efetividade das ações sociais: os resultados apresentados indicaram que a utilização desta ferramenta foi importante para a identificação de oportunidades para melhoria dos resultados, possibilitando ainda a prestação de informações para a Contabilidade Pública.

Segundo Kanji \& Moura e Sá, apud Lourenço \& Machado (2002), o Balanced Scorecard, tal como outras metodologias, apresenta pontos fortes e fracos. As forças do modelo BSC são:

- pôr junto, em um relatório único, muitos dos elementos aparentemente discrepantes da agenda competitiva das organizações;

- ter a habilidade de traduzir a visão e a estratégia da organização em objetivos tangíveis e medidas de desempenho;

- ser uma abordagem holística para a avaliação do desempenho organizacional;

- focar em num número limitado de medidas críticas;

- ter flexibilidade e adaptabilidade para atender a diversas organizações;

- apresentar senso de interdependência entre as várias áreas organizacionais ao considerar em conjunto todas as medidas operacionais importantes;

- ter forte enfoque em clientes e mercado;

- desenvolver entre os gerentes uma visão mais clara e compartilhada do que eles estão tentando alcançar e quais são as alavancas críticas a serem acionadas para o alcance desses objetivos;

- ser fácil de usar.

Segundo os mesmos autores, os pontos fracos são:

- ser um modelo conceitual, o que dificulta a conversão para um modelo de medição; 


\section{Revista Eletrônica de Ciência Administrativa (RECADM) - ISSN 1677-7387 \\ Faculdade Cenecista de Campo Largo - Coordenação do Curso de Administração \\ v. 4, n. 1, maio/2005 - http://revistas.facecla.com.br/index.php/recadm/}

- não mostrar claramente as interações entre critérios;

- não ser uma abordagem completa, uma vez que há ênfase em clientes e acionistas, desconsiderando outros importantes stakeholders (partes interessadas) como empregados, fornecedores e a comunidade;

- só enfocar resultado;

- enfocar, principalmente, medidas de desempenho tomadas a partir da cúpula diretora - medidas tomadas "de cima para baixo";

- não monitorar a competição, tornando a abordagem mais estática do que dinâmica;

- criar primeiramente, devido à estratégia downstream, compromisso externo, o que pode ser problemático, uma vez que faz surgir a possibilidade dos empregados se fixarem somente no que é medido.

\section{METODOLOGIA}

O estudo envolveu inicialmente a obtenção de informações teóricas, através de estudo exploratório, seguido do estudo formal descritivo, calcado numa pesquisa bibliográfica junto a autores consagrados na abordagem do tema tratado, principalmente Kaplan \& Norton, além da leitura de artigos específicos sobre o assunto existentes no mercado, com a finalidade de levantar os conceitos sobre Estratégia, indicadores de performance, objetivos, desdobramento estratégico, implementação de estratégias, etc. Dessa forma, fez-se uso de livros, revistas, jornais, dissertações, documentos impressos ou inseridos em meios eletrônicos, e vários tipos de comunicados científicos, entre outros, relativos à temática, seguido da consolidação do tema nas diversas abordagens já publicadas.

Não existe a pretensão, neste trabalho, de sedimentar todos os conceitos do Balanced Scorecard, buscando-se validar a viabilidade de sua implementação e aplicação nas diversas organizações, com a conseqüente melhoria alcançada nessa implementação.

\section{UTILIZAÇÃO DO BSC}

O momento atual, de acirrada competição, em que os produtos e serviços não são mais vendidos, mas comprados (o poder está do lado consumidor e não do lado do produtor), a busca pela excelência tem permeado a disputa pelo sucesso e sobrevivência no mercado. O avanço tecnológico, a expansão sem precedentes da comunicação, a crescente mobilidade do Capital e mão-de-obra (especialmente a qualificada em alta tecnologia), condições geopolíticas imprevisíveis, aumento da população e abertura de mercados internacionais não permitem mais fazer negócios como se fazia antes (BROHAWN, 1998). Chiavenato \& Cerqueira Neto (2003) concebem a eficácia organizacional como resultante de três condições básicas e essenciais a todas as empresas :

1. Alcance de objetivos organizacionais;

2. Manutenção da integridade do sistema interno;

3. Adaptação às mudanças do ambiente externo. 


\section{Revista Eletrônica de Ciência Administrativa (RECADM) - ISSN 1677-7387 \\ Faculdade Cenecista de Campo Largo - Coordenação do Curso de Administração v. 4, n. 1, maio/2005 - http://revistas.facecla.com.br/index.php/recadm/}

Desta forma, faz-se necessário estabelecer um sistema adequado de medição de performance organizacional, considerando-se os seguintes aspectos:

Quadro 1: Componentes de um sistema de medição

\begin{tabular}{|l|l|}
\hline \multicolumn{2}{|c|}{ Os Componentes de um Sistema de Medição } \\
\hline Identificação dos clientes da medição & Medir para quem? \\
\hline Definição dos objetivos da medição & Medir para quê? \\
\hline Identificação do sistema a ser medido & Medir o quê? \\
\hline Análise do sistema: processos e metas & $\begin{array}{l}\text { Quais as metas, os processos críticos e as } \\
\text { prioridades? }\end{array}$ \\
\hline Geração dos indicadores & $\begin{array}{l}\text { Quais os parâmetros e processos críticos } \\
\text { da organização? }\end{array}$ \\
\hline Montagem do sistema & Como será a operação do sistema? \\
\hline Implementação e aperfeiçoamento do sistema & Como fazer o sistema funcionar? \\
\hline
\end{tabular}
fonte: Chiavenato \& Cerqueira Neto (2003).

Solberg (1988) cita que a habilidade de aplicar o aprendizado via tentativa e erro para ajustar a performance, torna-se inútil em um ambiente em que mudanças ocorrem mais rapidamente que as lições aprendidas. Existe a necessidade de uma metodologia preditiva formal, baseada no entendimento de causa e efeito, expressa em diversas formas: equações, modelos matemáticos, simulações, algoritmos, aproximações, etc. O sistema de mensuração deve explicitar as relações (hipóteses) entre os objetivos (e as medidas) nas diversas perspectivas, de modo que possam ser gerenciadas e validadas. Segundo Chiavenato \& Cerqueira Neto (2003), há uma forte tendência no mundo de negócios: a substituição de sistemas passivos e retroativos de medição pura por sistemas dinâmicos e proativos focados na visão e ação estratégicas. Contudo, a maior parte de nossas avaliações é ainda subjetiva e carece de metodologia eficaz ou de uma técnica que permita o balança objetivo da situação. Com o Balanced Scorecard, as revisões e atualizações gerenciais deixam de analisar o passado, para aprender sobre o futuro, ao levar os executivos a discutir como os resultados passados foram alcançados, mas também se suas expectativas para o futuro permanecem viáveis.

Conforme Norton \& Kaplan (1997), o Balanced Scorecard, basicamente um mecanismo para implementação da estratégia (não para sua formulação), é mais do que um sistema de medidas táticas ou operacionais. Empresas o estão utilizando como um sistema de gestão estratégica para administrar a estratégia a longo prazo: norteado pela missão e visão, o Balanced Scorecard deve traduzir estas em objetivos e medidas tangíveis, destacando os processos mais críticos para a obtenção de um desempenho superior para clientes e acionistas, ao estabelecer metas com antecedência de três a cinco anos. Também incentiva o diálogo entre as unidades de negócios e os executivos e diretores da empresa, pelo fato de que suas perspectivas e, consequentemente, os indicadores utilizados, serem desenhados de forma a estabelecer uma relação causa e efeito entre eles, tornando explícita as relações existentes os objetivos nas diversas perspectivas. Assim sendo, as capacidades, sejam de redução de tempo, melhoria de Qualidade, e outras mais, acabam sendo transformadas em um desempenho financeiro superior. 
Revista Eletrônica de Ciência Administrativa (RECADM) - ISSN 1677-7387

Faculdade Cenecista de Campo Largo - Coordenação do Curso de Administração

v. 4, n. 1, maio/2005 - http://revistas.facecla.com.br/index.php/recadm/

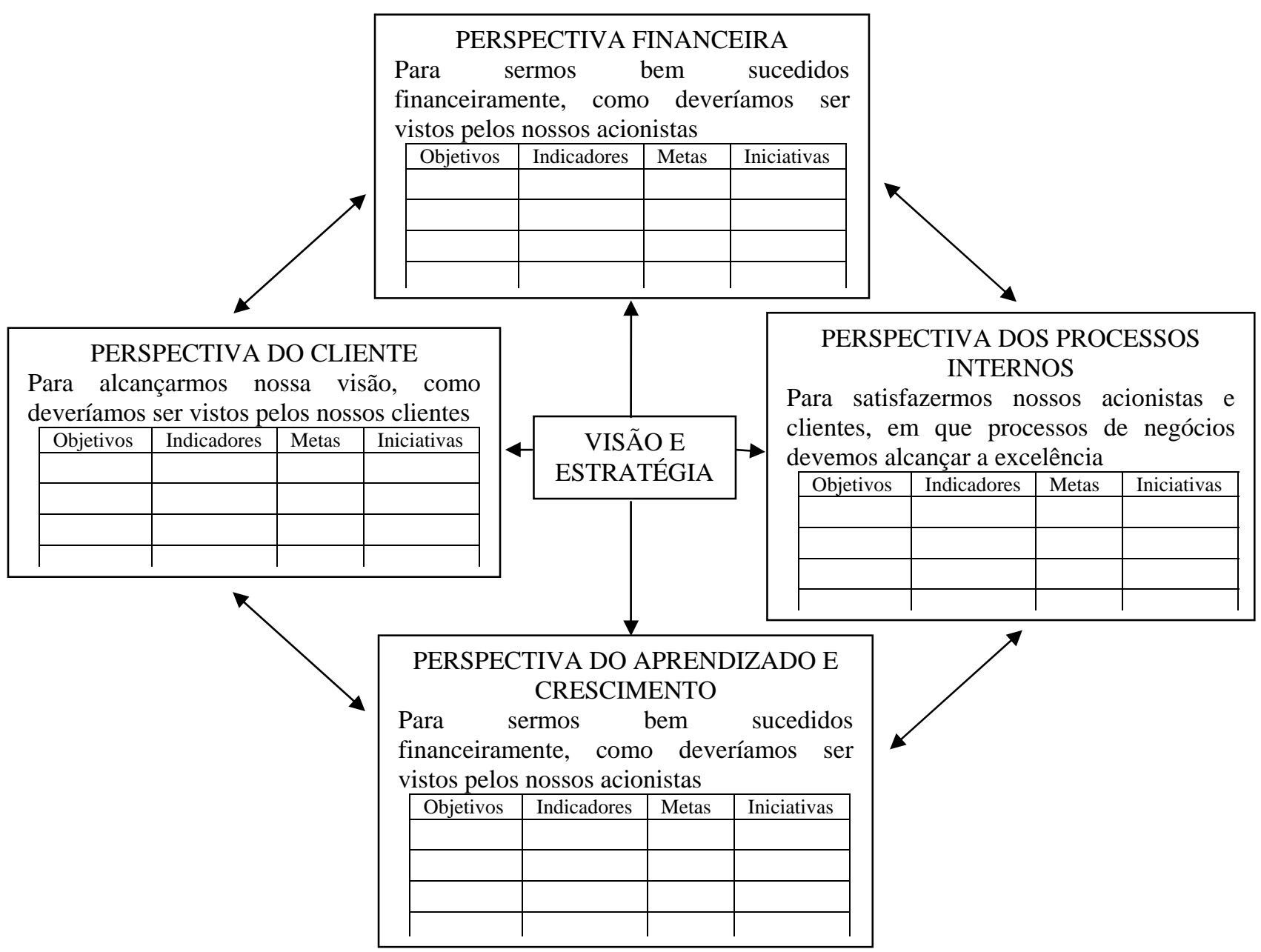

Figura 1: O Balanced Scorecard Fornece a Estrutura Necessária para a Tradução da Estratégia em Termos Operacionais (adaptado de NORTON \& KAPLAN, 1997)

Conforme Norton \& Kaplan (1997), toda medida selecionada para um scorecard deve então, fazer parte de uma cadeia de relações de causa e efeito que termina com os objetivos financeiros e representa um tema estratégico para a unidade de negócios. O scorecard deve contar a história da estratégia, partindo dos objetivos financeiros de longo prazo, relacionando-os à seqüência de ações necessárias em relação aos processos financeiros, de clientes, de processos internos e, por fim, de funcionários e sistemas, com o objetivo de produzir o desempenho econômico desejado a longo prazo. Tais processos são então encarados como perspectivas, sendo as mesmas: financeira, do cliente, dos processos internos e do aprendizado e crescimento. As perspectivas, com suas relações de causa e efeito são interativas. Por exemplo, ao prover treinamento para os funcionários, haverá um custo para este treinamento, o que impacta os resultados financeiros. 
Revista Eletrônica de Ciência Administrativa (RECADM) - ISSN 1677-7387

Faculdade Cenecista de Campo Largo - Coordenação do Curso de Administração

v. 4, n. 1, maio/2005 - http://revistas.facecla.com.br/index.php/recadm/

Os gerentes devem ajudar a definir e avaliar as relações hipotéticas de causa e efeito medindo a correlação entre duas ou mais variáveis. Se não forem encontradas as correlações esperadas, a organização terá evidências de que a teoria em que sua estratégia se apoia não está funcionando. A partir desta relação de causa e efeito, alia-se o desdobramento das perspectivas em objetivos mensuráveis, através de indicadores, metas e, por último, indicadores. As metas genéricas que aparecem ma maioria dos scorecards das empresas, conforme Norton \& Kaplan (1997), são:

Quadro 2: Medidas Estratégicas

\begin{tabular}{|l|l|}
\hline \multicolumn{1}{|c|}{ Perspectiva } & \multicolumn{1}{c|}{ Medidas Genéricas } \\
\hline Financeira & Retorno sobre o Investimento e o Valor Econômico Agregado \\
\hline Do Cliente & $\begin{array}{l}\text { Satisfação, Retenção, Participação de Mercado e Participação de } \\
\text { Conta }\end{array}$ \\
\hline Interna & $\begin{array}{l}\text { Qualidade, Tempo de Resposta, Custo e Lançamentos de Novos } \\
\text { Produtos }\end{array}$ \\
\hline $\begin{array}{l}\text { Aprendizado } \\
\text { Crescimento }\end{array}$ & $\begin{array}{l}\text { Satisfação dos Funcionários e Disponibilidade dos Sistemas de } \\
\text { Informação }\end{array}$ \\
\hline
\end{tabular}

Com a decomposição das medidas estratégicas de alto nível da unidade de negócios em medidas específicas de nível operacional, as relações de causa e efeito podem ser representadas conforme a figura 1, com todas as perspectivas interagindo entre si, em relações de causa e efeito, e sempre sendo irradiadas a partir da visão e da estratégia da organização.

\section{Perspectiva Financeira}

A perspectiva financeira é responsável por responder à questão "Se formos bem sucedidos com a nossa visão e aspiração estratégica, como seremos percebidos pelos acionistas ou donos?" Os Objetivos Estratégicos na perspectiva financeira são os orientadores dos outros objetivos e as medidas das outras perspectivas do Scorecard. Eles acabam tendo um duplo papel: definem o desempenho financeiro esperado da estratégia e servem de meta principal para os objetivos e medidas de todas as outras perspectivas. Estes objetivos financeiros devem incluir tanto os de longo prazo como os de curto e médio, de forma a produzir o resultado econômico desejado. Entre os principais temas financeiros apontados estão os seguintes: aumento da receita, melhoria dos custos, incremento da utilização dos ativos e redução dos riscos.

Conforme Norton \& Kaplan (1997), os objetivos financeiros podem diferir consideravelmente em cada fase do ciclo de vida de uma empresa. Os autores expõe as ações adequadas em cada uma das quatro fases principais: crescimento (ênfase no aumento de vendas - em novos mercados e para novos clientes - mantendo níveis de gastos adequados para o desenvolvimento de produtos e processos, sistemas, capacitação dos funcionários e criação de novos canais de marketing, vendas e distribuição), sustentação (ênfase em medidas financeiras tradicionais, como o retorno sobre o capital empregado, receita operacional e margem bruta, focados em redução de custos e melhoria de produtividade, de forma a reduzir os custos diretos e indiretos, inclusive compartilhando recursos com outras unidades de negócios), colheita (a meta não é maximizar o retorno sobre o investimento, mas 


\section{Revista Eletrônica de Ciência Administrativa (RECADM) - ISSN 1677-7387 \\ Faculdade Cenecista de Campo Largo - Coordenação do Curso de Administração \\ v. 4, n. 1, maio/2005 - http://revistas.facecla.com.br/index.php/recadm/}

maximizar o fluxo de caixa da unidade, como conseqüência de todos os investimentos feitos no passado e seus objetivos financeiros seriam o fluxo de caixa operacional e a diminuição da necessidade de Capital de giro) e saída (avaliar estrategicamente o portfólio, de forma a definir quais unidades devem continuar a existir, através da venda ou um encerramento ordenado das atividades).

\section{Perspectiva do Cliente}

Conforme Norton \& Kaplan (1997), o Balanced Scorecard traduz as declarações da missão e estratégia em objetivos específicos, baseados no mercado e nos clientes. Desta forma, a perspectiva dos clientes responde a uma grande questão: "Se formos bem sucedidos, como seremos percebidos pelos nossos clientes?" Ainda que muitas empresas tentem ativamente reduzir suas despesas gerais, administrativas e de vendas, conforme Norton \& Kaplan (1997), estas devem ser contrabalançadas no scorecard com outras medidas, como a capacidade de atendimento aos clientes, qualidade e desempenho, de modo que a redução de custos não interfira na realização de objetivos importantes nas perspectivas do cliente e dos processos internos. As empresas geralmente selecionam dois conjuntos de medidas para a perspectiva dos clientes: as medidas essenciais (comum a maioria das empresas) e vetores de desempenho (diferenciadores dos resultados fornecidos aos clientes).

As medidas essenciais aos clientes essenciais podem ser agrupadas em uma cadeia formal de relações de causa e efeito, conforme apresentado a seguir:

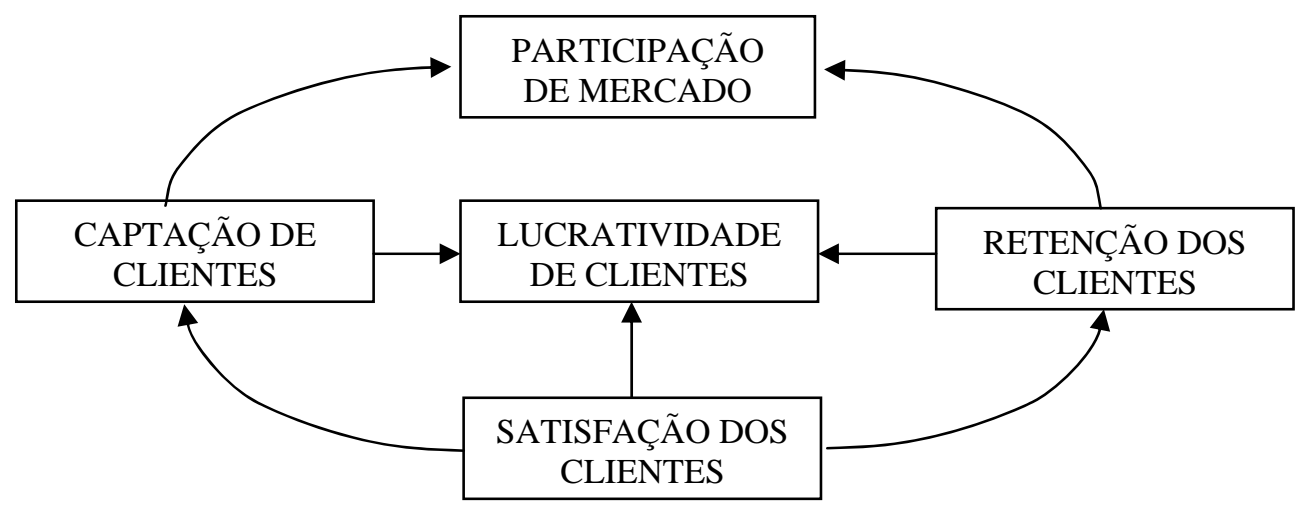

Figura 2: A Perspectiva do Cliente (NORTON \& KAPLAN, 1997)

Já os vetores de desempenho, ou propostas de valor, conforme Norton \& Kaplan (1997), são os atributos que os fornecedores oferecem, através de seus produtos e serviços, para gerar fidelidade e satisfação em segmentos-alvo. Ainda que variem de empresa para empresa e de setor para setor, alguns deles são observados em diversos scorecards, quais sejam: atributos dos produtos e serviços; relacionamento com os clientes e imagem e reputação.

\section{Perspectiva de Processos Internos}

As medidas dessa perspectiva estão voltadas para os processos internos que terão maior impacto na satisfação do cliente e na consecução dos objetivos internos da empresa. Como afirmado anteriormente, as medidas nas diversas perspectivas devem subordinar-se a perspectiva financeira, 


\section{Revista Eletrônica de Ciência Administrativa (RECADM) - ISSN 1677-7387 Faculdade Cenecista de Campo Largo - Coordenação do Curso de Administração v. 4, n. 1, maio/2005 - http://revistas.facecla.com.br/index.php/recadm/}

pois a simples imposição de medidas de desempenho aos processos existentes ou a processos reengenheirados pode estimular melhoria locais, mas dificilmente produzirá objetivos ambiciosos para clientes e acionistas (KAPLAN \& NORTON, 1997).

Desta forma, conforme Norton \& Kaplan (1997), é recomendável definir a cadeia de valor completa dos processos internos, no modelo sugerido a seguir:



Figura 3: A Perspectiva dos Processos Internos - Modelo da Cadeia de Valores Genérica (NORTON \& KAPLAN, 1997)

Percebe-se a similaridade dos elementos deste modelo com a representação do modelo de Excelência do Prêmio Nacional de Qualidade, com base nos seus oito critérios (Liderança, Estratégias e Planos, Clientes, Sociedade, Informações e Conhecimento, Pessoas, Processos e Resultados). Conforme Rivadeneira (1999), alguns ganhadores do Prêmio Nacional de Qualidade, o Citybank, em 1994, e a Alcoa, em 1996, mencionam que foi bastante útil a utilização conjunta do Balanced Scorecard junto ao modelo do PNQ. Há de se notar também a similaridade dos elementos presentes na cadeia de valores apresentada por Porter (1989).

Conforme Norton \& Kaplan (1997), todas as empresas tentam melhorar a qualidade, reduzir os tempos de ciclo, aumentar a produção, maximizar a produtividade e reduzir os custos de seus processos de negócios. Portanto, a concentração exclusiva em ganhos no tempo de ciclo, produtividade, qualidade e custo dos processos existentes talvez não leve a competências exclusivas. A menos que se possa superar o desempenho dos concorrentes em todos os processos de negócios, qualidade, tempo, produtividade e custo, tais melhorias aumentarão as chances de sobrevivência, mas não gerarão vantagens competitivas distintas e sustentáveis.

\section{Perspectiva da Inovação e Aprendizado}

Os objetivos e medidas para orientar o aprendizado surgem das necessidades identificadas nas três perspectivas anteriores, finanças, clientes e processos internos/inovação. Ao invés de realizar os levantamentos das necessidades de treinamento da maneira tradicional, as necessidades de aprendizagem surgem após uma constatação clara dos objetivos de performance em cada uma das perspectivas anteriores. Norton \& Kaplan (1997) citam que é improvável que as empresas sejam capazes de atingir suas metas de longo prazo para clientes e processos internos utilizando as 


\section{Revista Eletrônica de Ciência Administrativa (RECADM) - ISSN 1677-7387 \\ Faculdade Cenecista de Campo Largo - Coordenação do Curso de Administração \\ v. 4, n. 1, maio/2005 - http://revistas.facecla.com.br/index.php/recadm/}

tecnologias e capacidades atuais. Seguindo este raciocínio, é necessário identificar aonde a empresa e os seus colaboradores (as competências organizacionais e individuais) devem se destacar para obter uma alta performance. Os objetivos estratégicos desta perspectiva visam concretizar os planos de treinamento e desenvolvimento, respondendo tanto às necessidades estratégicas da empresa, como alinhando o desenvolvimento dos indivíduos com a organização.

Norton \& Kaplan (1997), a maioria das empresas traça objetivos para os funcionários extraídos de uma base comum de três medidas de resultados, quais sejam: satisfação dos funcionários, retenção de funcionários e produtividade dos funcionários, sendo que, mais uma vez estabelece-se uma relação de causa e efeito entre elas e os vetores de competência, infra-estrutura e clima, conforme pode ser observado na figura a seguir:



Figura 4: A Estrutura de Medicão do Aprendizado e Crescimento (NORTON \& KAPLAN, 1997)

Os autores defendem a existência de três categorias principais para a perspectiva de aprendizado e crescimento:

1. Capacidade dos Funcionários

2. Capacidades dos Sistemas de Informação

3. Motivação, Empowerment e Alinhamento 
Revista Eletrônica de Ciência Administrativa (RECADM) - ISSN 1677-7387

Faculdade Cenecista de Campo Largo - Coordenação do Curso de Administração

v. 4, n. 1, maio/2005 - http://revistas.facecla.com.br/index.php/recadm/

Conforme Norton \& Kaplan (1997), as estratégias, os objetivos e as medidas das unidades operacionais individuais, provavelmente são tão diversos que não podem ser facilmente agregados em um scorecard corporativo em perspectivas que não seja a financeira: os Balanced Scorecards das unidades podem ser personalizados, mas todos tem uma unidade de propósito e foco derivada do âmbito corporativo, sendo que uma das maiores dificuldades é explicar as metas que as diversas partes têm para o empreendimento conjunto.

Averson \& Rohm (2002) estabelecem um ciclo de feedback operacional e estratégico com o uso do Balanced Scorecard e seus indicadores, além do BSC como processo decisório, conforme os fluxos mostrados a seguir:

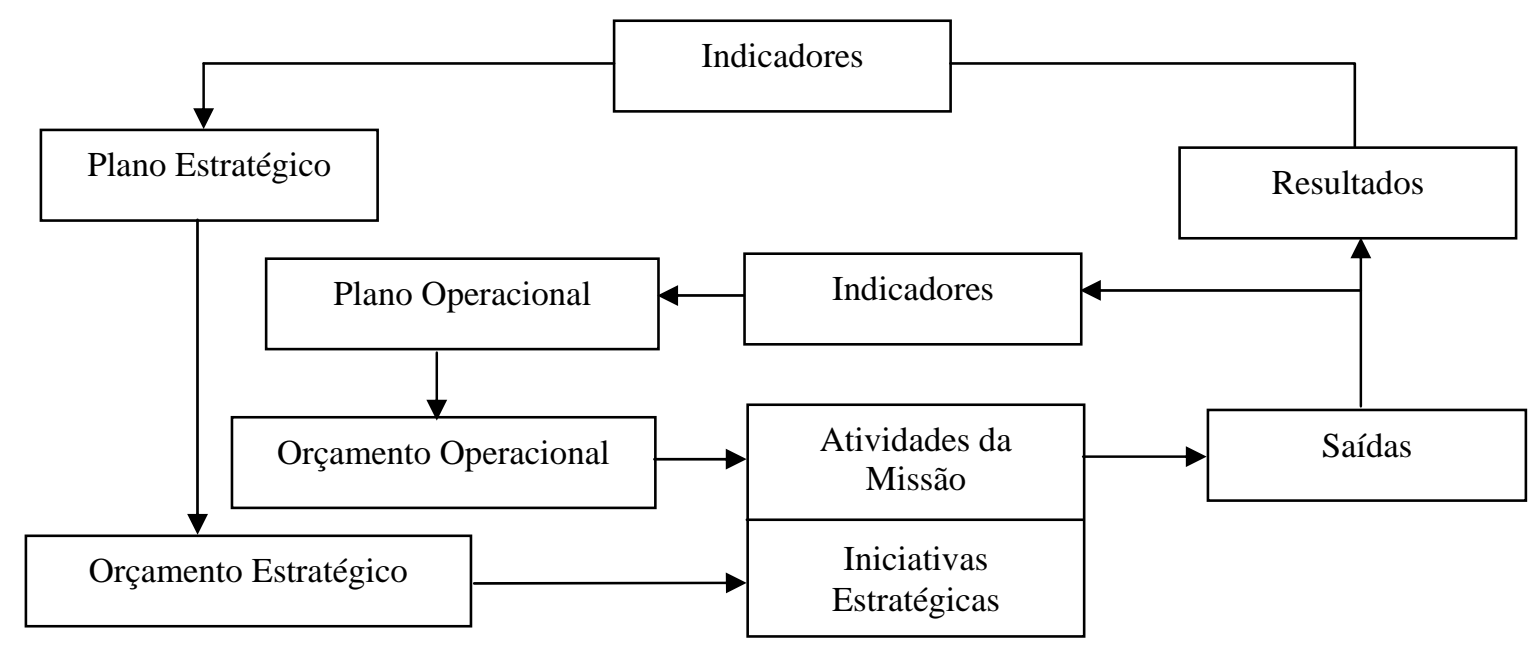

Figura 5: Feedback Estratégico e Operacional (fonte: Arverson \& Rohm, 2002)



- Missão

- Visão

- Temas Estratégicos

- Perspectivas

- Objetivos

- Indicadores

- Metas

- Iniciativas

- Plano de Capital

- Orçamento Operacional

- Projetos Especiais

- Análise 
Revista Eletrônica de Ciência Administrativa (RECADM) - ISSN 1677-7387

Faculdade Cenecista de Campo Largo - Coordenação do Curso de Administração

v. 4, n. 1, maio/2005 - http://revistas.facecla.com.br/index.php/recadm/

Um processo claro de monitoramento, controle e revisão da estratégia baseado no Balanced Scorecard, muitas vezes não é estabelecido, o que compromete o sucesso da iniciativa e a conseqüente aquisição de benefícios. Norton \& Kaplan (1997) propõe um processo para criação do Balanced Scorecard composto de quatro etapas:

1. Definição da arquitetura de indicadores;.

2. Consenso em função dos objetivos estratégicos;

3. Escolha e elaboração de indicadores;.

4. Elaboração do plano de implementação.

A figura a seguir mostra um mapa de processo desenvolvido por Best Practices, LLC (2002), mostrando os processos chave de negócio, a partir de um levantamento feito com 24 diferentes companhias.

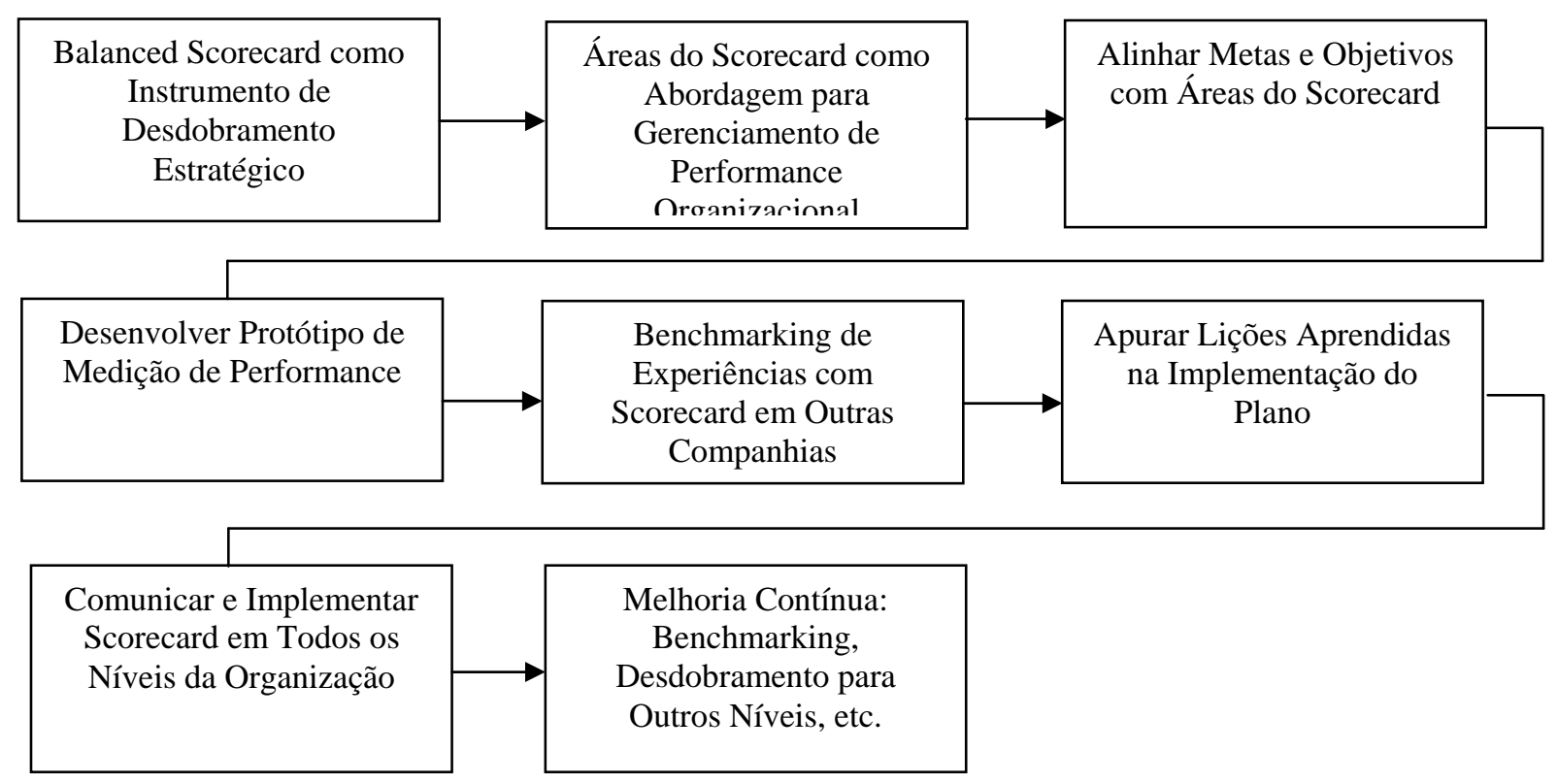

Figura 7: A Progressão do Balanced Scorecard (fonte: Best Practices, 2002)

\section{CONCLUSÃO E PROPOSTAS DE NOVAS PESQUISAS}

A construção do Balanced Scorecard impulsiona as interfaces da empresa a agir na mesma direção para produzir os resultados finais objetivados, operacionalizndo a visão, missão e aspiração 


\section{Revista Eletrônica de Ciência Administrativa (RECADM) - ISSN 1677-7387 \\ Faculdade Cenecista de Campo Largo - Coordenação do Curso de Administração v. 4, n. 1, maio/2005 - http://revistas.facecla.com.br/index.php/recadm/}

estratégica em objetivos tangíveis e mensuráveis. Conforme citado por Norton \& Kaplan (1997), o Balanced Scorecard não substitui o sistema de medições cotidiana da empresa: as medidas do scorecard são selecionadas de modo a direcionar a atenção de executivos e funcionários para os fatores capazes de levar a empresa a grandes realizações. Conforme cresce a adoção do Balanced Scorecard, as empresas constatam que ele pode ser utilizado para:

- Esclarecer e obter consenso em relação à estratégia.

- Comunicar a estratégia a toda a empresa.

- Alinhar as metas departamentais e pessoais à estratégia.

- Associar os objetivos estratégicos com metas de longo prazo e orçamentos anuais.

- Identificar e alinhar as iniciativas estratégicas.

- Realizar revisões estratégicas periódicas e sistemáticas.

- Obter feedback para aprofundar o conhecimento da estratégia e aperfeiçoá-la.

Segundo Chiavenato \& Cerqueira Neto (2003), em 1997 diversas empresas já haviam vivido experiências com o BSC e outras estavam desejando implementá-lo em seus negócios. Desde o lançamento do Balanced Scorecard, ele foi adotado por aproximadamente metade das organizações citadas na "Fortune 500" e seu uso continua crescendo (NIVEN, 2002). A edição especial da Harvard Business Review, comemorativa de seu $75^{\circ}$. aniversário (setembro-outubro de 1997) cita o Balanced Scorecard como sendo um dos quinze mais importantes conceitos gerenciais introduzidos via artigos nesta revista (COBBOLD \& LAWRIE, 2002). No Brasil, segundo dados da Symnetics, a consultoria que representa a Balanced Scorecard Collaborative, de Kaplan e Norton, cerca de 40 companhias 0 adotam, dentre elas, Gerdau, Petrobrás, Aracruz Celulose, Copel, Siemens e Oxileno (HERZOG, 2003).

Exemplos como os vistos acima mostram a potencialidade do modelo desenvolvido por Norton e Kaplan, pela sua capacidade de suportar o processo decisório e de desdobramento estratégico. $\mathrm{O}$ uso da tal ferramenta, apesar de ter sido disponibilizado há mais de dez anos, é ainda insipiente no Brasil, basicamente restrito a algumas corporações, pode ser expandido para setores diversos, visando o aumento de competência produtiva e de serviços, permitindo uma melhoria substancial na geração de riqueza e no bem estar da população. Tais aplicações podem servir de base de um novo estudo, que permitiria mostrar a importância da utilização de modelos matemáticos no suporte à tomada de decisão estratégica nas organizações.

\section{REFERÊNCIAS BIBLIOGRÁFICAS}

AFRICA NEWS SERVICE, Embracing the Concept of Value-Based Management. Johannesburg, Aug 15, 2001 p1008227u0183.

ARVERSON, PAUL \& ROHM, HOWARD. Rolling it All Together: a Balanced Scorecard Approach. Balanced Scorecard Institute, 2002. Disponível em www.balancedscorecard.org/. 
Revista Eletrônica de Ciência Administrativa (RECADM) - ISSN 1677-7387

Faculdade Cenecista de Campo Largo - Coordenação do Curso de Administração v. 4, n. 1, maio/2005 - http://revistas.facecla.com.br/index.php/recadm/

BALANCED SCORECARD COLLABORATIVE. Balanced Scorecard Functional Standards, Release 1.0a, Balanced Scorecard Collaborative, Inc, Lincoln, 2000, MA/USA.

BEST PRACTICES, Executive Summary: Developing the Balanced Scorecard. Best Practices, LLC. Chapel Hill/NC, 2002.

BROHAWN, DAWN. Value-Based Management: A Framework for Equity and Efficiency in the Workplace. Center for Economic and Social Justice, 1998 - disponível em http://www.cesj.org/vbm/articles-vbm/cwp-vbm.htm. Acesso em 24/fevereiro/2003.

CHIAVENATO, IDALBERTO \& CERQUEIRA NETO, EDGARD, Administração Estratégica: em Busca do Desempenho Superior - Uma Abordagem além do Balanced Scorecard, Editora Saraiva, São Paulo, 2003.

COBBOLD, IAN \& LAWRIE, GAVIN, Classification of Balanced Scorecards Based on their Effectiveness as Strategic Control or Management Control Tool, 2GC Limited, Berkshire, UK, Presented at PMA 2002, Boston/MA, July 2002.

CORDEIRO, NADIR et al, Modelo de Gestão Estratégica para Organizações Prestadoras de Serviço. In: Congresso Nacional de Excelência em Gestão, 2002, Niterói, Anais (Niterói, UFF LATEC, 2002).

FUNDAÇÃO PARA O PRÊMIO NACIONAL DA QUALIDADE, Critérios de Excelência: o Estado da Arte da Gestão para a Excelência do Desempenho e o Aumento da Competitividade, Fundação para o Prêmio Nacional da Qualidade, São Paulo, 2003.

HERNANDES, CARLOS et al, Combinando o Balanced Scorecard com a Gestão do Conhecimento, Caderno de Pesquisas em Administração, São Paulo, v. 01, no. 12, 20. trimestre 2000.

HERZOG, ANA, Pensar, Planejar e Fazer, Revista Exame, 12 março 2003. Páginas 52-56.

KALLÁS, DAVID, A Abordagem Microeconômica do Comportamento do Consumidor Proposta por Kevin Lancaster como Complemento ao Modelo de Gestão Baseado no Balanced Scorecard, Symnetics Business Transformation, 2001. Disponível em www.symnetics.com.br. Acesso em 3 dez. 2003.

$\mathrm{KOCH}, \mathrm{NÉLIO}$. Quadro Equilibrado de Indicadores de Desempenho para a Gestão Estratégica Empresarial - Aplicação a uma Pequena Empresa da Área de Serviço Público de Energia Elétrica, 2002. Dissertação (Mestrado em Engenharia de Produção). Escola de Engenharia, Universidade Federal do Rio Grande do Sul. Porto Alegre.

LANCASTER, KELVIN, A New Approach to Consumer Theory, Journal of Political Economy, pág. 132-57, 1966.

LANCASTER, KELVINS, Modern Consumer Theory, Billing \& Sons, 1991.

LOURENÇO, JORGE \& MACHADO, ANA, O Balanced Scorecard como Ferramenta Gerencial para o Aprendizado Organizacional. In: Congresso Nacional de Excelência em Gestão, 2002, Niterói, Anais (Niterói, UFF LATEC, 2002). 
Revista Eletrônica de Ciência Administrativa (RECADM) - ISSN 1677-7387

Faculdade Cenecista de Campo Largo - Coordenação do Curso de Administração v. 4, n. 1, maio/2005 - http://revistas.facecla.com.br/index.php/recadm/

MATHEUS, LEANDRO, Fatores a Serem Considerados na Estruturação do Controle de Projetos de Investimento - Uma Abordagem da Utilização do Balanced Scorecard, Revista Produção On Line, ABEPRO - Associação Brasileira de Engenharia de Produção, v.2, n.2, 2002. Disponível em www.procucaoonline.inf.br/artigos/zip/03.zip. Último acesso em 11 dezembro 2002.

NIVEN, PAUL, Balanced Scorecard Step-by-step; Maximizing Performance and Maintaining Results, John Willey \& Sons, $1^{\text {st }}$ edition, Mar, 152002.

NORTON, DAVID \& KAPLAN, ROBERT, Estratégia em Ação: Balanced Scorecard, Editora Campus, 1997.

PHADNIS, SHREE. Selection of Project Metrics, i Six Sigma Corporation. Disponível em www.isixsigma.com. Acesso em 8 outubro 2001.

PORTER, MICHAEL, Vantagem Competitiva: Criando e Sustentando um Desempenho Superior. Editora Campus, Rio de Janeiro, 1989.

PRADO, LAURO, Guia Balanced Scorecard, 1a. edição e-Book, LJP e-Zine, 2002. Disponível em http://lauroprado.tripod.com/ezine/. Acesso em 19 dez 2003.

PROFETA, ROGÉRIO \& GOLDSZMIDT, RAFAEL, Balanced Scorecard: Uma Revisão de Literatura. In: V Simpósio da Administração da Produção, Logística e Operações Internacionais SIMPOI, 2002, São Paulo, Anais (São Paulo, FGV-EAESP, 2002).

RADÜNZ, RICARDO, Sistema de Informação para a Avaliação de Desempenho de Atacados, Baseado na Metodologia Balanced Scorecard, 2002. Tese de Mestrado em Engenharia de Produção. Universidade Federal de Santa Catarina - UFSC, Programa de Pós-Graduação em Engenharia de Produção, Florianópolis/SC.

RIVADENEIRA, RICARDO, El Balanced Scorecard (BSC) y sus Relaciones com la Calidad, Martinez Consulting Group, Colômbia, Fundation Latinoamericana de la Calidad, 29 outubro 1999, Disponível em www.calidad.org. Acesso em 30 nov. 1999.

SANCHEZ, KRISTIANE et al. Balanced Scorecard: Inovação na Gestão de Organizações Hospitalares. In: V Simpósio da Administração da Produção, Logística e Operações Internacionais SIMPOI, 2002, São Paulo, Anais (São Paulo, FGV-EAESP, 2002).

SANTANA, CUSTÓDIO, Balanced Scorecard - Uma Proposta de Modelo para Aplicação no Setor Varejista - Ramo Supermercado, Symnetics Business Transformation, 2002. Disponível em www.symnetics.com.br. Acesso em 03 janeiro 2004.

SAUAIA, ANTÔNIO, Preferências de Homens e Mulheres que Participam de Programas de Aprendizagem com Jogos de Empresas. São Paulo, 2000. Artigo FEA/USP, UFRGS.

SOARES, CRISTINA, Desenvolvimento de uma Sistemática de Elaboração do Balanced Scorecard para Pequenas Empresas, 2001. Dissertação (Mestrado em Engenharia de Produção). Escola de Engenharia, Universidade Federal do Rio Grande do Sul. Porto Alegre.

SOLBERG, JAMES, Integrated Manufacturing Systems: An Overview - Design and Analysis of Integrated Manufacturing Systems, USA. The National Academy of Science, 1988. 